\title{
GluR6/KA2 Kainate Receptors Mediate Slow-Deactivating Currents
}

\author{
Andrea Barberis, Shankar Sachidhanandam, and Christophe Mulle \\ Laboratoire Physiologie Cellulaire de la Synapse, Centre National de la Recherche Scientifique Unité Mixte de Recherche 5091, Bordeaux Neuroscience \\ Institute, University of Bordeaux 2, 33077 Bordeaux, France
}

Kainate receptors (KARs) are ionotropic glutamate receptors contributing to EPSCs with a slow-decaying component that is likely essential for synaptic integration. The slow kinetics of KAR-EPSCs markedly contrasts with the fast kinetics reported for recombinant KARs expressed in heterologous systems, for reasons that remain unexplained. Here we have studied the properties of recombinant heteromeric GluR6/KA2 receptors, which compose synaptic KARs. We report that, in response to brief glutamate applications, currents mediated by recombinant GluR6/KA2 receptors, but not GluR6 receptors, decay with a time course similar to KAR-EPSCs. Model simulations suggest that, after brief agonist exposures, GluR6/KA2 currents undergo slow deactivation caused by the stabilization of partially bound open states. We propose, therefore, that the GluR6/KA2 gating features could contribute to the slow KAR-EPSC decay kinetics.

Key words: kainate receptor; KAR-EPSC kinetics; gating properties; desensitization; glutamate receptor; synaptic transmission

\section{Introduction}

EPSCs mediated by kainate receptors (KARs) display remarkably slow decay kinetics. This property is believed to underlie the summation of excitatory inputs and to participate in the efficacy of spike transmission under repeated presynaptic activity (Castillo et al., 1997; Vignes and Collingridge, 1997; Mulle et al., 1998; Frerking and Ohliger-Frerking, 2002; Goldin et al., 2007; Yang et al., 2007). In contrast, recombinant KARs activated by exogenous glutamate pulses mediate currents decaying more than one order of magnitude faster than KAR-EPSCs (Heckmann et al., 1996; Swanson et al., 2002; Bowie et al., 2003). To explain the causes of the slow KAREPSC kinetics, it has been first hypothesized that KARs would be located extrasynaptically and activated by glutamate spillover. This possibility was then ruled out based on the observations that reduction of glutamate diffusion and inhibition of glutamate reuptake failed to change the amplitude and kinetics of KAR-EPSCs (Castillo et al., 1997; Bureau et al., 2000; Kidd and Isaac, 2001). It has also been proposed that the specific behavior of synaptic KARs could be determined by the binding of modulatory proteins to the receptors' cytoplasmic domains. However, the alterations of KAR gating properties induced by interacting proteins reported so far are unlikely to be the main determinant for the differences between KAR-EPSCs and recombinant KAR-mediated currents (Garcia et al., 1998; Bowie et al., 2003; Laezza et al., 2007).

Despite the fact that GluR6/KA2 heteromeric receptors are the

Received March 20, 2008; revised May 5, 2008; accepted May 5, 2008.

This work was supported by the Centre National de la Recherche Scientifique (CNRS), the Ministère de la Recherche of France and the Conseil Régional d'Aquitaine, and the European Commission (EUSynapse, Contract LSH-2004019055) to C.M. A.B. was supported by a grant from the CNRS, and S.S. by a fellowship from the Fondation pour la Recherche Médicale. We thank Drs. David Perrais, Nelson Rebola, and Marco Beato for helpful discussion.

Correspondence should be addressed to either Andrea Barberis or Christophe Mulle at the above address. E-mail: andrea.barberis@iit.it or mulle@u-bordeaux2.fr.

DOI:10.1523/JNEUROSCI.1204-08.2008

Copyright $\odot 2008$ Society for Neuroscience $\quad 0270-6474 / 08 / 286402-05 \$ 15.00 / 0$ most abundant KAR subtype in the brain (Petralia et al., 1994) and compose synaptic KARs in the hippocampus and the cerebellum (Pinheiro and Mulle, 2006), their gating properties have been poorly investigated with respect to GluR6 homomers. In addition, recombinant receptors studied in heterologous systems are commonly activated by long pulses of glutamate in conditions substantially different from those occurring during synaptic transmission (Clements et al., 1992). In the present study, we have therefore compared the properties of GluR6 and GluR6/KA2 receptors expressed in HEK293 cells and used glutamate pulses that attempted to approximate the glutamate transient attained during synaptic transmission. Interestingly, contrary to homomeric GluR6-mediated currents, the decay kinetics of GluR6/KA2 currents activated by brief agonist exposures decayed 10-fold slower than those evoked by the long ones and matched the KAR-EPSC decay kinetics. Such GluR6/KA2 gating behavior could be modeled by using a kinetic scheme previously proposed for AMPA-type glutamate receptors (Robert and Howe, 2003). Our data suggest that the dynamic conditions of GluR6/KA2 receptor activation are crucial in determining the slow time course of KAR-EPSC decay, hence the role of postsynaptic KARs in synaptic integration.

\section{Materials and Methods}

Human embryonic kidney 293 cell line and cDNA transient transfection. Human embryonic kidney 293 cells (293-Hektor no. 05030204; European Collection of Cell Cultures) were grown and plated as previously reported (Coussen et al., 2005). HEK293 cells were transiently cotransfected with GluR6a(Q) and EGFP cDNAs in the ratio 1:1 or GluR6a(Q), $\mathrm{KA} 2$, and EGFP cDNAs in the ratio 1:3:1 (unless stated otherwise).

Electrophysiological recordings (HEK293 cells). Electrophysiological recordings in HEK293 cells were performed in the whole-cell configuration of the patch-clamp technique using the EPC10 amplifier (HEKA Elektronik). Experiments on HEK293 cells were performed at room temperature (22$24^{\circ} \mathrm{C}$ ). External solution contained the following (in mM): $145 \mathrm{NaCl}, 2 \mathrm{KCl}$, $2 \mathrm{CaCl}_{2}, 2 \mathrm{MgCl}_{2}, 10$ glucose, and $10 \mathrm{HEPES}$ (adjusted to $320 \mathrm{mOsm}$ and $\mathrm{pH}$ 
A

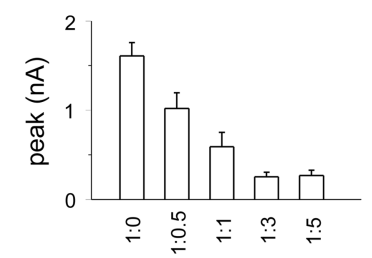

C

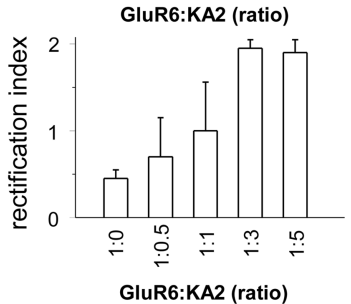

E

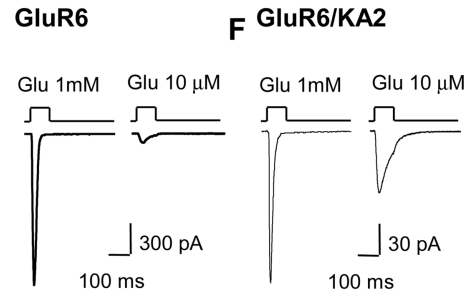

G

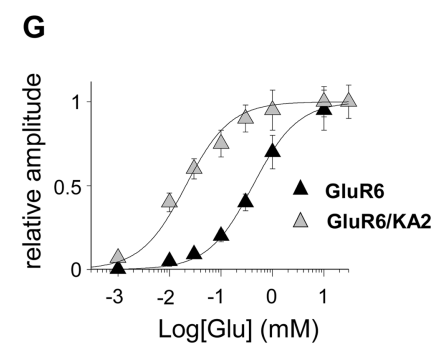

H

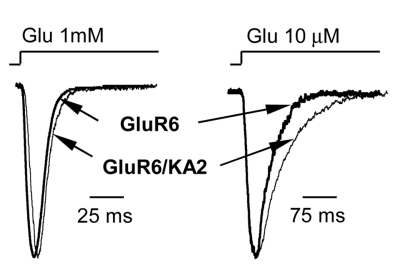

$\mathbf{J}$

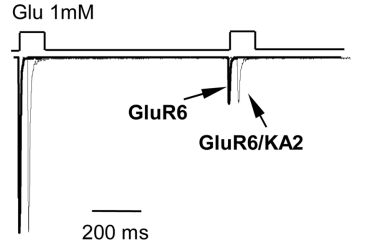

B GluR6

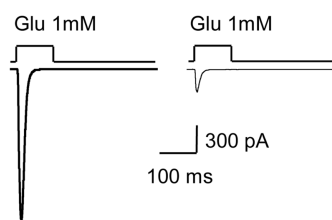

D

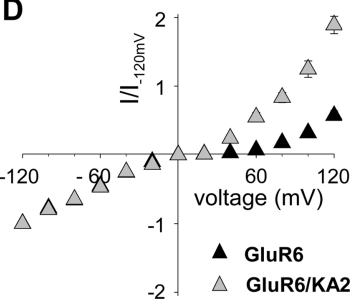

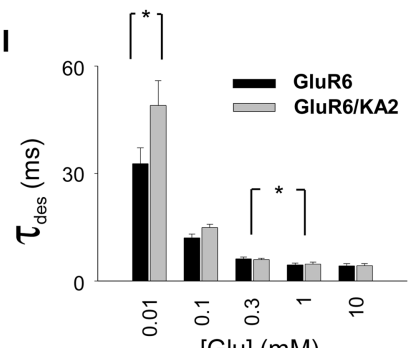

K

[Glu] (mM)

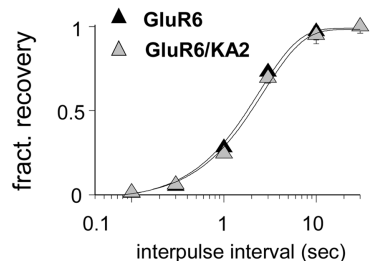

Figure 1. Properties of GluR6- and GluR6/KA2-mediated currents evoked by long glutamate pulses. $A$, Dependence of the current peak amplitude on GluR6:KA2 CDNA ratio. Currents were elicited by glutamate pulses ( $1 \mathrm{~mm}, 100 \mathrm{~ms})$. B, Typical GluR6 and GluR6/KA2 current responses to glutamate (1 mm, $100 \mathrm{~ms})$. GluR6 and KA2 subunits were transfected at the ratio 1:3. C, Dependence of the rectification index (ratio between the current obtained at membrane potential $+120 \mathrm{mV}$ and $-120 \mathrm{mV}$ ) on GluR6:KA2 cDNA ratio. $D$, Current-voltage ( $I-\eta$ ) curves for current mediated by GluR6 (black triangles) and GluR6/KA2 (gray triangles). GluR6 and KA2 CDNAs were transfected at the ratio 1:3. $\boldsymbol{E}, \boldsymbol{F}$, Typical GluR6-mediated (E) and GluR6/KA2-mediated $(\boldsymbol{F})$ currents elicited by glutamate ( $1 \mathrm{~mm}$ and $10 \mu \mathrm{m}$ ). G, Dose-response curve for GluR6 (black triangles) and GluR6/KA2 receptors (gray triangles). $\boldsymbol{H}$, Same traces as in $\boldsymbol{E}$ and $\boldsymbol{F}$ normalized and superimposed. $\boldsymbol{I}$, Summary of the desensitization kinetics at different [Glu]. ${ }^{*} p<0.05$. J, Typical example of GluR6 and GluR6/KA2 current responses to paired-pulse protocol (1 mm, $100 \mathrm{~ms}$ pulse length, $1 \mathrm{~s}$ gap). $\boldsymbol{K}$, Time course of the recovery from desensitization (GluR6 and GluR6/KA2 receptors, black and gray triangles, respectively). In paired-pulse experiments, we only compared traces showing the same peak amplitude when evoked by either 1.5 or 100 ms glutamate pulses. $\tau_{\text {des }}$ desensitization time constant; fract., fractional.

7.4 with $\mathrm{NaOH}$ ). Patch pipettes were pulled from borosilicate glass capillaries, and their resistance ranged from 4 to $5 \mathrm{M} \Omega$ when filled with intracellular solution containing the following (in mM): $122 \mathrm{CsCl}, 2 \mathrm{CaCl}_{2}, 2 \mathrm{MgCl}_{2}, 11$ BAPTA [1,2-bis(2-aminophenoxy)ethane- $N, N, N^{\prime}$-tetra-acetic acid], 10 HEPES, and $4 \mathrm{Na}_{2} \mathrm{ATP}$ (adjusted to $300 \mathrm{mOsm}$ and $\mathrm{pH} 7.2$ with $\mathrm{CsOH}$ ). Signals (currents) were acquired using the Patchmaster software, filtered at 3 $\mathrm{kHz}$, sampled at $50 \mathrm{kHz}$, and further analyzed using Igor Pro 5.0. When
GluR6 and KA2 cDNAs were cotransfected, recordings showing rectification index $<1.5$ were discarded (see Results). In paired-pulse experiments, we compared traces showing the same peak when evoked by either brief or long pulses.

Electrophysiological recordings in hippocampal slices. Transverse hippocampal slices $(350 \mu \mathrm{m}$ thick) were prepared as detailed by Ruiz et al. (2005). KAR-EPSCs were recorded at $33^{\circ} \mathrm{C}$ in the presence of picrotoxin $(100 \mu \mathrm{M})$, CGP55845 (5 $\mu \mathrm{M})$, APV $(50 \mu \mathrm{M})$, and GYKI $53655(50 \mu \mathrm{M})$. Intracellular pipette solution contained the following (in mM): $120 \mathrm{~mm} \mathrm{~K}$-gluconate, $20 \mathrm{KCl}, 10$ HEPES, 10 EGTA, $2 \mathrm{NaATP}, 2 \mathrm{MgCl}_{2}$, and 1 $\mathrm{CaCl}_{2}$. The access and input resistances were monitored throughout the experiments using a voltage step. A patch pipette filled with HEPESbuffered external solution was placed at the inner border of the dentate gyrus to stimulate mossy fibers to evoke unitary Mf-KAR-EPSCs in CA3 pyramidal cells. Mf-KAR-EPSCs were recorded at $-70 \mathrm{mV}$ at the frequency of $1 \mathrm{~Hz}$. Mossy fiber responses were characterized by the marked facilitation of EPSCs after switching stimulus frequency from 0.1 to $1 \mathrm{~Hz}$ and by their sensitivity to the group 2 and 3 mGluR agonist LCCG-1 (10 $\mu \mathrm{M}$ ) added routinely at the end of the experiment. Signals were acquired and processed as already detailed for the experiments in HEK293 cells.

Drug application. Glutamate was applied to HEK293 cells using an ultrafast perfusion system using a piezoelectric-driven theta-glass application pipette (Jonas, 1995) [piezoelectric translator: P-245.30 (Physik Instrumente); theta glass tubing: Harvard Apparatus]. The open-tip recordings of the liquid junction potentials revealed that the 10-90\% exchange of solution occurred within $\sim 100 \mu \mathrm{s}$. This value was obtained by setting the solution rate flow to $10 \mathrm{ml} / \mathrm{h}$ through a theta pipette with tip diameter $\sim 100 \mu \mathrm{m}$. The speed of the solution exchange around the whole cell was also estimated by the $10-$ $90 \%$ onset of the membrane depolarization induced by application of high $(25 \mathrm{~mm})$-potassium saline. In these conditions the $10-90 \%$ rise time was $\sim 400 \mu \mathrm{s}$ (see supplemental Fig. 1, available at www. jneurosci.org as supplemental material). To minimize the solution exchange time in the whole-cell configuration, currents were recorded from small HEK293 cells, showing a membrane capacitance $<8$ $\mathrm{pF}$. In some cells $(<25 \%)$, because the time exposure was too brief to reach the maximal peak amplitude, currents evoked by $1.5 \mathrm{~ms}$ pulses showed a reduction in peak amplitude with respect to those evoked by $100 \mathrm{~ms}$ pulses. Traces showing a peak amplitude reduction $>15 \%$ were discarded. In fastperfusion experiments (in HEK293 cells), kainate was added to both control and agonist-containing solution. In slice experiments, kainate was bath applied.

Analysis. The decaying phase of the currents was fitted with a function in the following form: $y(t)=\Sigma A_{i} \exp \left(-t / \tau_{i}\right)$, where $A_{i}$ are the fractions of respective components $\left(\Sigma A_{i}=1\right)$ and $\tau_{i}$ are the time constants. In double-exponential fits, the weighted deactivation time constant $\tau_{\mathrm{w}}$ was calculated using the formula $\tau_{\mathrm{w}}=\Sigma A_{i} \tau_{i}$. A maximum of two exponential components were used. The fractional recovery from desensitization was expressed as $r=I_{2} / I_{1}$, where $I_{1}$ and $I_{2}$ represent the first and the second peak amplitude, respectively. Dose-response curves were obtained by normalizing the current amplitude at the differ- 
A

GluR6

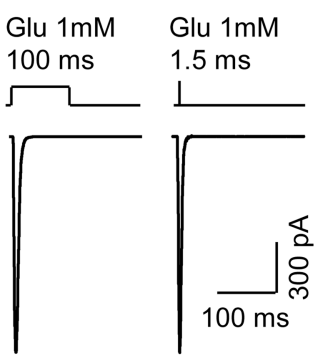

B


C

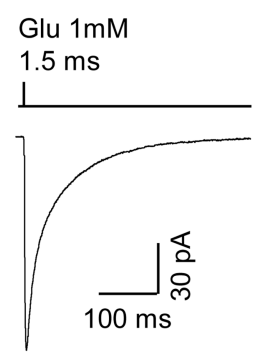

GluR6

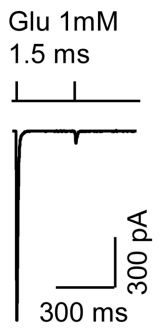

\section{GluR6/KA2}



D



$\mathbf{E}$

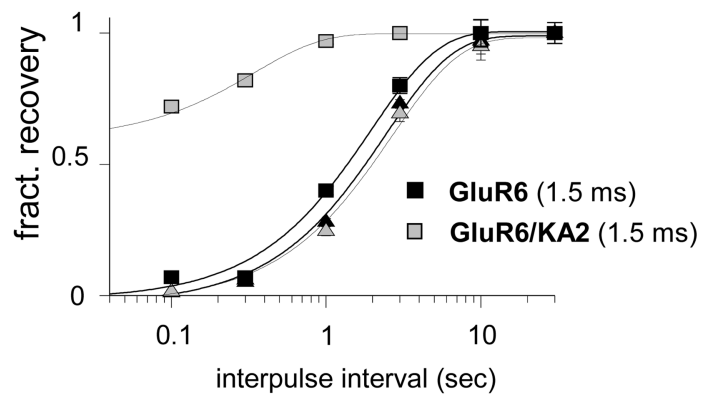

Figure 2. GluR6/KA2 decay kinetics depends on stimulation pulse length. $A, B$, GluR6 currents and GluR6/KA2 currents evoked by either long (100 ms) or brief (1.5 ms) glutamate pulses. $C$, Paired pulses for GluR6- and GluR6/KA2-mediated currents (1 mm, $1.5 \mathrm{~ms}$ pulse length, $300 \mathrm{~ms}$ gap). D, Summary of the decay kinetics for GluR6 and GluR6/KA2 currents (black and gray bars, respectively) evoked by increasing glutamate pulse duration. $\boldsymbol{E}$, Time course of recovery from desensitization for GluR6 and GluR6/KA2 receptors (black and gray squares, respectively) obtained with 1.5 ms pulses superimposed on that obtained with 100 ms pulses (same as that shown in Fig. 1 M; black and gray triangles for GluR6 and GluR6/KA2 receptors, respectively). fract., Fractional.

ent $[\mathrm{Glu}]$ to the responses obtained at $[\mathrm{Glu}] 30 \mathrm{~mm}$. Data were fitted using the equation $y=1 /\left(1+\mathrm{EC}_{50} /[\mathrm{Glu}]\right)$. Values are expressed as mean \pm SEM. Paired and unpaired Student's $t$ tests were used for data comparison.

\section{Results}

GluR6 and GluR6/KA2 receptors expressed in HEK293 cells mediate currents with distinct $I-V$ relationships

Cotransfection of GluR6 and KA2 cDNAs is expected to yield a mixture of homomeric GluR6 and heteromeric GluR6/KA2 [because KA2 subunits do not form functional homomers (Herb et al., 1992; Ren et al., 2003; Nasu-Nishimura et al., 2006)]. Previous studies showed that after cotransfection of GluR6 and KA2 in heterologous systems, the amount of KA2 subunit expressed at the cell membrane surface critically depends on the GluR6:KA2 cDNA ratio (Nasu-Nishimura et al., 2006). Glutamate pulses (1 $\mathrm{mM}, 100 \mathrm{~ms}$ ) delivered to cells transfected with GluR6 elicited current responses of large amplitude $(1650 \pm 65 \mathrm{pA}$, at a holding potential of $-40 \mathrm{mV} ; n=25$ ) (Fig. $1 A, B)$. By cotransfecting GluR6 and KA2, the current peak amplitude considerably decreased. The reduction in current amplitude depended on the relative amount of KA2 cDNA and reached saturation with a GluR6:KA2 plasmid concentration ratio of $1: 3(252 \pm 52 \mathrm{pA} ; n=$ 16) (Fig. 1A). The KA2-dependent reduction in the current peak amplitude suggests that the cotransfection of GluR6 and KA2 plasmids produces surface expression of functional GluR6/KA2 receptors. In addition, the cotransfection of GluR6 and KA2 plasmids yielded the formation of functional GluR6/KA2 receptors with novel properties. Cotransfection of GluR6 and KA2 yielded currents with a markedly different $I-V$ (current-to-voltage) relationship from that of homomeric GluR6 currents. The rectification index (current recorded at membrane voltage $+120 \mathrm{mV}$ normalized to the current at $-120 \mathrm{mV}$ ) increased in a dose- dependent manner by increasing the relative amount of KA2, and saturated at a GluR6:KA2 ratio of 1:3 (0.45 \pm 0.10 and $1.90 \pm$ 0.20 for GluR6 and GluR6:KA2, respectively) (Fig. 1C,D). The fourfold increase of the rectification index observed at a GluR6: KA2 cDNA ratio of 1:3 implies that cotransfection yields surface expression of functional GluR6/KA2 heteromeric receptors. Further increasing the relative amount of KA2 did not lead to additional changes in $I-V$ relationship or amplitude, strongly suggesting that, at 1:3 ratio, a homogeneous population of GluR6/KA2 heteromeric KARs is present at the cell membrane surface.

GluR6 and GluR6/KA2 receptors display different glutamate sensitivity and similar desensitization kinetics at high [Glu] We further compared homomeric and heteromeric recombinant KARs in terms of functional properties relevant to synaptic transmission. The glutamate dose-response curves for GluR6 and GluR6/KA2 receptors indicated markedly higher affinity and/or efficacy for GluR6/KA2 receptors than for GluR6 (GluR6, EC ${ }_{50}=$ $427 \pm 23 \mu \mathrm{M}, n=5$; GluR6/KA2, $\mathrm{EC}_{50}=15 \pm 2 \mu \mathrm{M}, n=8$ ) (Fig. $1 E-G)$. GluR6 and GluR6/KA2 currents evoked by 100 ms glutamate pulses ( $1 \mathrm{mM}$ ) displayed similar desensitization onset kinetics (GluR6, $4.5 \pm 0.4 \mathrm{~ms}$; GluR6/KA2, $4.7 \pm 0.3 \mathrm{~ms}$ ) [Fig. $1 \mathrm{H}$ (left),I]. Lowering the glutamate concentration below $300 \mu \mathrm{M}$ led to slower desensitization kinetics for both GluR6 and GluR6/KA2 currents [Fig. $1 \mathrm{H}$ (right),I], as already described for homomeric GluR6 receptors (Heckmann et al., 1996; Paternain et al., 2003). Moreover, at low glutamate concentrations, the apparent desensitization was significantly slower for GluR6/KA2 currents than for GluR6. The time course of recovery from desensitization, studied using a paired-pulse protocol, was fitted by a monoexponential function exhibiting similar time constants for GluR6 and GluR6/KA2 receptors $[1 \mathrm{~mm}$ Glu, $2.4 \pm 0.2 \mathrm{~s}(n=6)$ and $2.7 \pm$ 
A

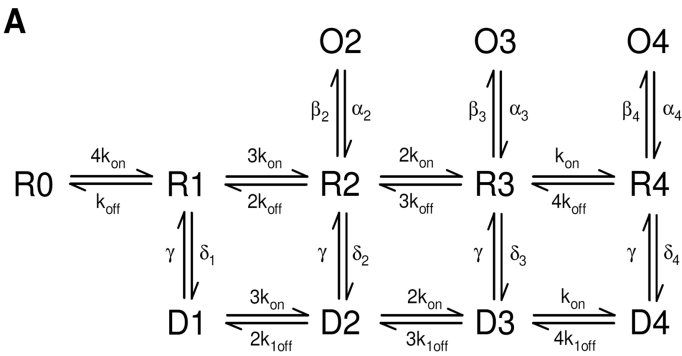

simulated GluR6

B


C
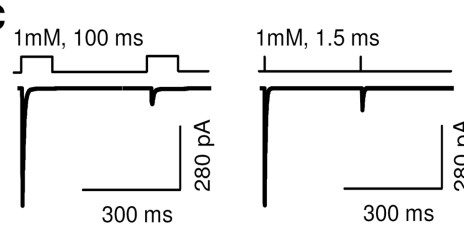

simulated GluR6/KA2

E
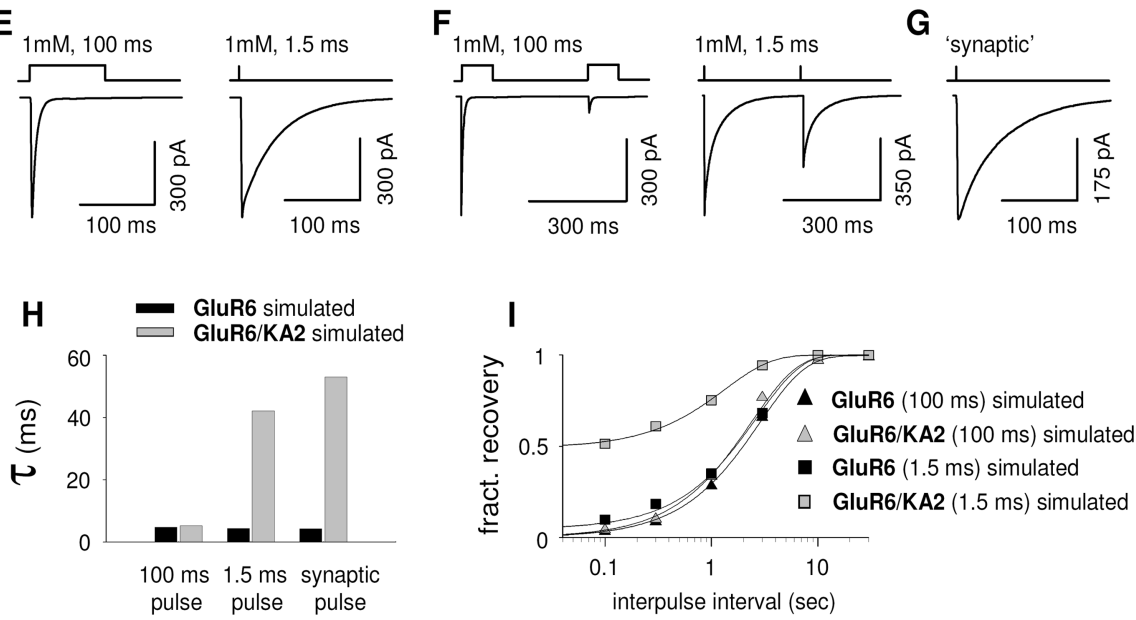

Figure 3. Model simulation. A, Kinetic scheme previously proposed by Robert and Howe (2003). The rate constants used to simulate the behavior of GluR6 and GluR6/KA2 receptors are listed in supplemental Table 1 (available at www.jneurosci.org as supplemental material). Simulated current traces were obtained by activating 1000 channels at the holding potential of $-90 \mathrm{mV}$. When brief (1.5 ms) pulses were applied, the input waveform was trapezoidal, matching the whole-cell depolarization time course induced by $1.5 \mathrm{~ms}$ application of $25 \mathrm{~mm}$ potassium concentration saline, as detailed in supplemental Figure 1 (available at www.jneurosci.org as supplemental material). $\boldsymbol{B}, \boldsymbol{E}$, Simulated GluR6- and GluR6/KA2-mediated current evoked by $1 \mathrm{~mm}, 100 \mathrm{~ms}$ glutamate pulse (left) and by $1 \mathrm{~mm}, 1.5 \mathrm{~ms}$, glutamate pulse (right). $C, F$, Simulated paired-pulse protocol for GluR6 and GluR6/KA2 receptors [100 ms, $1 \mathrm{~mm}, 300 \mathrm{~ms}$ gap (left) and $1.5 \mathrm{~ms}, 1 \mathrm{~mm}, 300 \mathrm{~ms}$ gap (right)].D, G, Simulated GluR6-and GluR6/KA2-mediated current evoked by a synaptic-like glutamate exposure. The synaptic-like glutamate pulse was assumed to be exponential (see supplemental Model Simulations, available at www.jneurosci.org as supplemental material). $\boldsymbol{H}$, Summary of the decay time constants for simulated GluR6 and GluR6/KA2 currents elicited by brief (1.5 ms), long (100 ms), and synaptic-like glutamate pulses. $I$, Time course of the recovery from desensitization for GluR6 and GluR6/KA2 receptors obtained with $1.5 \mathrm{~ms}$ pulses and 100 ms pulses (same color and symbol code as in Fig. 2E). fract., Fractional.

$0.3 \mathrm{~s}(n=8)$, respectively] (Fig. $1 L, M)$. At glutamate concentrations 30 and $10 \mathrm{~mm}$, for GluR6, the $10-90 \%$ current rise times were $0.7 \pm 0.2(n=6)$ and $0.8 \pm 0.1(n=8) \mathrm{ms}$, respectively, indicating solution exchange time occurring in the submillisecond range (see also supplemental Fig. 1, available at www. jneurosci.org as supplemental material). The rise times of currents obtained at 1 and $0.1 \mathrm{~mm}$ glutamate were $1.1 \pm 0.2 \mathrm{~ms}(n=$ $15)$ and $12.5 \pm 3.6 \mathrm{~ms}(n=6)$, in agreement with Heckmann et al. (1996). Those values were not statistically different from those obtained in GluR6/KA2 $(p>0.05)$. 'synaptic'
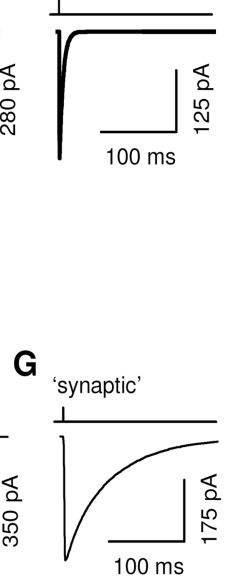

Distinct behavior of GluR6- and GluR6/ KA2-mediated currents in response to brief glutamate activation

When glutamate currents are evoked by brief neurotransmitter exposures, such as occur during synaptic transmission, it is not clear to what extent the current decay is shaped by deactivation or by fast entry into desensitization. We therefore studied the kinetics of GluR6 and GluR6/KA2 currents evoked by brief exogenous glutamate. GluR6 currents evoked by brief glutamate pulses ( $1 \mathrm{~mm}, 1.5 \mathrm{~ms}$ ) displayed decay time constant $\tau=3.4 \pm 0.3 \mathrm{~ms}$, a value significantly faster to that obtained with long (100 ms) glutamate pulses (Fig. $2 A, D)$. Unexpectedly, GluR6/KA2 currents evoked by the brief glutamate pulses decayed biexponentially, and the weighted-average decay time constant was 10 -fold longer than that observed in currents evoked by long pulses $\left(\tau_{\text {fast }}=18.5 \pm\right.$ $2.1 \mathrm{~ms} ; \tau_{\text {slow }}=73.4 \pm 3.8 \mathrm{~ms} ; A_{\text {fast }}=$ $0.48 \pm 0.02 ; \tau_{\mathrm{w}}=46 \pm 2.5 \mathrm{~ms}$ ) (Fig. $2 B, D)$. The same result was obtained in excised patch configuration (see supplemental Fig. 2, available at www. jneurosci.org as supplemental material). Although much less pronounced, the dependence of the GluR6 currents decay kinetics on the pulse duration was opposite in GluR6/KA2 currents (Fig. 2D). The recovery from desensitization of GluR6 currents evoked by brief glutamate pulses was not significantly different from that recorded with long pulses $(\tau=2.1 \pm 0.3 \mathrm{~s})$ (Fig. 2E, black squares superimposed on the same curves as in Fig. $1 \mathrm{M}$ ). In contrast, in response to brief glutamate pulses, GluR6/KA2 receptors displayed much lower desensitization accumulation than GluR6 [Fig. 2C (right),E].

\section{Model simulations}

Computer model simulations were used to provide mechanistic insight into the GluR6 and GluR6/KA2 gating properties. For this purpose, we adopted the model backbone by Robert and Howe (2003) already used to simulate the behavior of GluR1 homomeric receptors (Fig. 3A). We first optimized the rate constants to match the experimentally observed kinetic behavior of GluR6 receptors (see also supplemental Model Simulations, available at www. jneurosci.org as supplemental material). Using the rate constant set listed in supplemental Table 1 (available at www.jneurosci.org as supplemental material), we were able to reproduce the basic feature of the GluR6-mediated currents (Fig. 3B-E). Subsequently, we introduced the minimal changes in the GluR6 model rate constants to reproduce the experimental behavior of GluR6/KA2 currents, including (1) lower entry into desensitization, lower exit from desensitization, and higher opening/closing ratio from the partially bound states; and (2) reduction by a factor of approximately three of the 
unbinding rate constants (supplemental Table 1, available at www. jneurosci.org as supplemental material). Such a rate constant set allowed modeling the GluR6/KA2 dependence of the decay kinetics on the glutamate pulse duration (Fig. $3 \mathrm{~F}-\mathrm{I}$ ). According to our simulations, unlike GluR6, GluR6/KA2 partially bound states would be more favored to open rather than desensitize, whereas from the fully bound state, both receptor subtypes would rapidly desensitize. GluR6/KA2 receptors therefore display fast desensitization but slow deactivation, the latter being prevalent after activation by brief glutamate exposures. Next, we attempted to simulate currents evoked by an exponential function input waveform supposed to match the time course of the glutamate concentration in the synaptic cleft (see Materials and Methods). In these conditions, GluR6/KA2 currents decayed $\sim 20 \%$ slower than those evoked by $1.5 \mathrm{~ms}$ pulses, whereas GluR6 currents were unchanged (Fig. $3 D, G, H$ ). The $\mathrm{EC}_{50}$ values predicted by our model simulations (see supplemental Table 1, available at www.jneurosci.org as supplemental material) were 300 and $20 \mu \mathrm{M}$ for GluR6 and GluR6/KA2, respectively. These values qualitatively matched the experimentally observed values (350 and $15 \mu \mathrm{M}$ for GluR6 and GluR6/KA2, respectively) (Fig. 1C).

\section{Discussion}

Our data show that, in response to brief exogenous glutamate application, GluR6/KA2 receptors, but not homomeric GluR6, are intrinsically capable of slow deactivation kinetics. This finding is interesting because (1) heteromeric GluR6/KA2 receptors comprise a major population of synaptic KARs in the brain; (2) synaptic neurotransmitter exposure occurring in the synaptic cleft is brief, as approximated in these experimental conditions; (3) GluR6/KA2 currents evoked by brief glutamate pulses undergo poor desensitization, a feature that could play an important role in the linear summation of KAR-EPSCs observed at mossy fiber synapses under repetitive stimulation (Castillo et al., 1997); and (4) slower deactivation than the apparent desensitization of receptors represents an uncommon feature for glutamate receptors. Overall, our data suggest that the gating properties of GluR6/KA2 could be important in determining KAR-EPSC kinetics. Experiments comparing the effects of low kainate concentrations on recombinant and synaptic KARs support this hypothesis (see supplemental text and supplemental Fig. 3, available at www.jneurosci.org as supplemental material).

Studies performed in hippocampal slices obtained from $\mathrm{KA}^{-/-}$ mice showed an $\sim 30 \%$ acceleration of the KAR-EPSC kinetics in slices (Contractor et al., 2003). This observation confirms that KA2 subunit participates in shaping KAR-EPSCs but also indicates that, even in the absence of KA2 subunit, the KAR-EPSCs are markedly slower than currents mediated by GluR6 homomeric recombinant receptors. The closely related KA1 subunit that is abundantly expressed in CA3 pyramidal cells could participate in synaptic KARs and replace KA2 subunits in $\mathrm{KA} 2^{-/-}$mice. Until a double mutant (KA1-KA2 ${ }^{-/-}$) is available, it will be difficult in fact to address the role of KA1 and KA2 in the KAREPSC kinetics. Overall, KA2 acts as an accessory subunit that controls in concert both the functional properties of KARs and their expression at the membrane surface (Pinheiro and Mulle, 2006), similarly to transmembrane-associated proteins TARPs for AMPA receptors (Cho et al., 2007; Milstein et al., 2007).

\section{References}

Bowie D, Garcia EP, Marshall J, Traynelis SF, Lange GD (2003) Allosteric regulation and spatial distribution of kainate receptors bound to ancillary proteins. J Physiol (Lond) 547:373-385.

Bureau I, Dieudonne S, Coussen F, Mulle C (2000) Kainate receptormediated synaptic currents in cerebellar Golgi cells are not shaped by diffusion of glutamate. Proc Natl Acad Sci USA 97:6838-6843.
Castillo PE, Malenka RC, Nicoll RA (1997) Kainate receptors mediate a slow postsynaptic current in hippocampal CA3 neurons. Nature 388:182-186.

Cho CH, St-Gelais F, Zhang W, Tomita S, Howe JR (2007) Two families of TARP isoforms that have distinct effects on the kinetic properties of AMPA receptors and synaptic currents. Neuron 55:890-904.

Clements JD, Lester RA, Tong G, Jahr CE, Westbrook GL (1992) The time course of glutamate in the synaptic cleft. Science 258:1498-1501.

Contractor A, Sailer AW, Darstein M, Maron C, Xu J, Swanson GT, Heinemann SF (2003) Loss of kainate receptor-mediated heterosynaptic facilitation of mossy-fiber synapses in KA2-/-mice. J Neurosci 23:422-429.

Coussen F, Perrais D, Jaskolski F, Sachidhanandam S, Normand E, Bockaert J, Marin P, Mulle C (2005) Co-assembly of two GluR6 kainate receptor splice variants within a functional protein complex. Neuron 47:555-566.

Frerking M, Ohliger-Frerking P (2002) AMPA receptors and kainate receptors encode different features of afferent activity. J Neurosci 22:7434-7443.

Garcia EP, Mehta S, Blair LA, Wells DG, Shang J, Fukushima T, Fallon JR, Garner CC, Marshall J (1998) SAP90 binds and clusters kainate receptors causing incomplete desensitization. Neuron 21:727-739.

Goldin M, Epsztein J, Jorquera I, Represa A, Ben-Ari Y, Crépel V, Cossart R (2007) Synaptic kainate receptors tune oriens-lacunosum moleculare interneurons to operate at theta frequency. J Neurosci 27:9560-9572.

Heckmann M, Bufler J, Franke C, Dudel J (1996) Kinetics of homomeric GluR6 glutamate receptor channels. Biophys J 71:1743-1750.

Herb A, Burnashev N, Werner P, Sakmann B, Wisden W, Seeburg PH (1992) The KA-2 subunit of excitatory amino acid receptors shows widespread expression in brain and forms ion channels with distantly related subunits. Neuron 8:775-785.

Jonas P (1995) Fast application of agonists to isolated membrane patches. In: Single-channel recording, Ed 2 (Sakmann B, Neher E, eds), pp 231243. New York: Plenum.

Kidd FL, Isaac JTR (2001) Kinetics and activation of postsynaptic kainate receptors at thalamocortical synapses: role of glutamate clearance. J Neurophysiol 86:1139-1148.

Laezza F, Wilding TJ, Sequeira S, Coussen F, Zhang XZ, Hill-Robinson R, Mulle C, Huettner JE, Craig AM (2007) KRIP6: a novel BTB/kelch protein regulating function of kainate receptors. Mol Cell Neurosci 34:539-550.

Milstein AD, Zhou W, Karimzadegan S, Bredt DS, Nicoll RA (2007) TARP subtypes differentially and dose-dependently control synaptic AMPA receptor gating. Neuron 6:905-918.

Mulle C, Andreas S, Pérez-Otaño I, Dickinson-Anson H, Castillo PE, Bureau I, Maron C, Gage FH, Mann JR, Bettler B, Heinemann SF (1998) Altered synaptic physiology and reduced susceptibility to kainate induced seizures in GluR6-deficient mice. Nature 392:601-604.

Nasu-Nishimura Y, Hurtado D, Braud S, Tang TT, Isaac JT, Roche KW (2006) Identification of an endoplasmic reticulum-retention motif in an intracellular loop of the kainate receptor subunit KA2. J Neurosci 26:7014-7021.

Paternain AV, Cohen A, Stern-Bach Y, Lerma J (2003) A role for extracellular $\mathrm{Na}^{+}$in the channel gating of native and recombinant kainate receptors. J Neurosci 23:8641-8648.

Petralia RS, Wang YX, Wenthold RJ (1994) Histological and ultrastructural localization of the kainate receptor subunits, KA2 and GluR6/7, in the rat nervous system using selective antipeptide antibodies. J Comp Neurol 349:85-110.

Pinheiro P, Mulle C (2006) Kainate receptors. Cell Tissue Res 236:457-482.

Ren Z, Riley NJ, Garcia EP, Sanders JM, Swanson GT, Marshall J (2003) Multiple trafficking signals regulate kainate receptor KA2 subunit surface expression. J Neurosci 23:6608-6616.

Robert A, Howe JR (2003) How AMPA receptor desensitization depends on receptor occupancy. J Neurosci 23:847-858.

Ruiz A, Sachidhanandam S, Utvik JK, Coussen F, Mulle C (2005) Distinct subunits in heteromeric kainate receptors mediate ionotropic and metabotropic function at hippocampal mossy fiber synapses. J Neurosci 25:11710-11718.

Swanson GT, Green T, Sakai R, Contractor A, Che W, Kamiya H, Heinemann SF (2002) Differential activation of individual subunits in heteromeric kainate receptors. Neuron 34:589-598.

Vignes M, Collingridge GL (1997) The synaptic activation of kainate receptors. Nature 388:179-182.

Yang EJ, Harris AZ, Pettit DL (2007) Synaptic kainate currents reset interneuron firing phase. J Physiol (Lond) 578:259-273. 